\title{
Residues 41V and/or 210D in the NP protein enhance polymerase activities and potential replication of novel influenza (H7N9) viruses at low temperature
}

Wenfei Zhu', Xiaohui Zou', Jianfang Zhou, Jing Tang and Yuelong Shu ${ }^{*}$

\begin{abstract}
Background: The influenza A (H7N9) virus emerged in the spring of 2013 in China. It contained six internal genes from Y280-like H9N2 viruses, which have co-circulated with G1-like lineage viruses throughout poultry in China. Accompanied with continuous reassortment among H7N9 and H9N2 viruses in poultry, it is possible for H7N9 viruses to acquire internal genes of G1-lineage viruses. Thus, it is important to evaluate potential impact of G1-like viruses on the H7N9 viruses.
\end{abstract}

Findings: We used in vitro assays of polymerase activities and growth kinetics to evaluate the potential contribution of G1-like virus genes to the replication abilities of H7N9 viruses. Two mutations in the NP protein (41V and/or 210D) could enhance H7N9 RNP activities, especially at low temperature $\left(33^{\circ} \mathrm{C}\right.$, which is similar to the temperature of human upper respiratory tract). Meanwhile, G1 viruses with V41I or D210E substitutions exhibited poor growth ability in the early infection stage at low temperature. The D210E substitution also reduced the replication ability of G1 virus at 12 and 24 hour post infection at $37^{\circ} \mathrm{C}$. In both tested temperatures, V41I could compensate for the defective virus replication induced by the D210E mutation.

Conclusions: Mutations 41V and/or 210D in the NP protein conferred improved RNP activity in H7N9 viruses and promoted the replication ability of H9N2 viruses, particularly at lower temperature. Substitutions at these two positions may promote the replication ability of H7N9 viruses in low temperature and thus might contribute to viral transmissibility. While these two residues have not yet been observed in H7N9 viruses, attention should be devoted to these two residues.

Keywords: Influenza A (H7N9) virus, NP mutations, Low temperature replication

\section{Findings}

The zoonotic transmission of a novel influenza A (H7N9) virus into humans in February 2013 in Eastern China has become a global concern [1]. This H7N9 virus was a reassortant between $\mathrm{H} 7$ and $\mathrm{N} 9$ viruses, with six internal genes from Y280-lineage H9N2 avian influenza viruses. Although studies in avian and mammalian models such as chickens, pigs, ferrets, and non-human primates have shown that this virus is of low or mild

\footnotetext{
* Correspondence: yshu@cnic.org.cn

${ }^{\dagger}$ Equal contributors

National Institute for Viral Disease Control and Prevention, China CDC, Key Laboratory for Medical Virology, National Health and Family Planning
} Commission, 155 Changbai Road, Beijing 102206, P.R China pathogenicity [2-5], H7N9 infection in humans has often led to severe outcomes $[1,6,7]$. Glutamic acid (E)-tolysine (K) substitution at position 627 in $\mathrm{PB} 2$, one of the important molecular markers of mammalian-adapted avian influenza viruses, was reported to be associated with enhanced virulence of the highly pathogenic H5N1 and H7N7 avian influenza viruses in mice $[8,9]$, and responsible for viral replication at lower temperatures $\left(33^{\circ} \mathrm{C}\right)$, allowing enhanced growth in the upper respiratory tract of mammals and efficient transmission of the viruses [10-13]. Although there has been limited humanto-human transmission [14], no highly transmissible cases have been reported for the novel H7N9 virus. This 
virus is reported to have more efficient replication in the lower respiratory tract than the upper respiratory tract [15], which merits studying the role of viral factors in transmissibility, especially viral replication at low temperature $\left(33^{\circ} \mathrm{C}\right)$.

Multiple genotypes of H7N9 viruses have been reported via continuous reassortant of their internal genes with H9N2 viruses in poultry [16]. Additionally, two different H9N2 lineages, Y280-like and G1-like, cocirculate in poultry in mainland China [17-19], raising the possibility for H7N9 viruses to reassort with G1-like virus. To test whether four RNP complex genes (PB2, $\mathrm{PB} 1, \mathrm{PA}$, and NP) of G1-like H9N2 viruses confer any advantages to those of H7N9 viruses, we first tested all recombinant RNP activities between A/Quail/Hong Kong/G1/1997 (H9N2, G1) and A/Anhui/1/2013 (H7N9, $\mathrm{AH} 1$ ) at $33^{\circ} \mathrm{C}$ and $37^{\circ} \mathrm{C}$. Temperatures of $33^{\circ} \mathrm{C}$ and $37^{\circ} \mathrm{C}$ were used to approximate the conditions of human upper and lower respiratory tracts, respectively. Reporter plasmid polI-Gluc [20] was co-transfected with expression plasmids encoding PB2, PB1, PA, and the NP of G1 or AH1 into 293T cells using the PolyFect (Qiagen, Valencia, CA, USA) reagent, according to the manufacturer's instructions. Gluc activity in supernatants was analyzed in 24 hours post transfection using a Gluc assay kit (New England Biolabs,
Beverly, MA, USA) and normalized to AH1 RNP activity. G1 exhibited about 2.5-fold higher RNP activity than AH1 at $37^{\circ} \mathrm{C}$ (Figure $1 \mathrm{~B}$ ), while at $33^{\circ} \mathrm{C}$ the RNP of G1 showed much less activity than AH1 (Figure 1A). PB2-E627K could have contributed to the better RNP function of AH1 at $33^{\circ} \mathrm{C}$, because the $\mathrm{G} 1$ virus contained the $627 \mathrm{E}$ residue at $\mathrm{PB} 2$ protein. In addition, the AH1-NP led to decreased RNP activity of $\mathrm{G} 1$ at $37^{\circ} \mathrm{C}$, while the G1-NP enhanced the RNP activity of AH1 at both temperatures (Figure 1A, B).

For a more detailed investigation of the role of different NPs in viral replication and transcription, we constructed four NP plasmids from different subtype viruses: A/ bar-headed goose/Qinghai/1/2005 (H5N1, QH1), A/ Guangzhou/333/1999 (H9N2, GZ), A/California/04/2009 (2009pdmH1N1, CA04), and A/Puerto Rico/8/1934 (H1N1, PR8). We co-transfected polI-Gluc with plasmids expressing the RdRp subunits of AH1 plus different NPs into 293T cells, and RNP activities were tested. G1-NP was the only plasmid that significantly enhanced RNP activity of $\mathrm{AH} 1$ at $33^{\circ} \mathrm{C}$ (Figure $1 \mathrm{C}$ ), and also increased RNP activity at $37^{\circ} \mathrm{C}$ about 1.25 fold (Figure 1D).

We then compared the sequences of the six tested NPs: AH1, G1, QH1, GZ, CA04, and PR8. G1-NP possessed two specific residues, $41 \mathrm{~V}$ and $210 \mathrm{D}$, while the
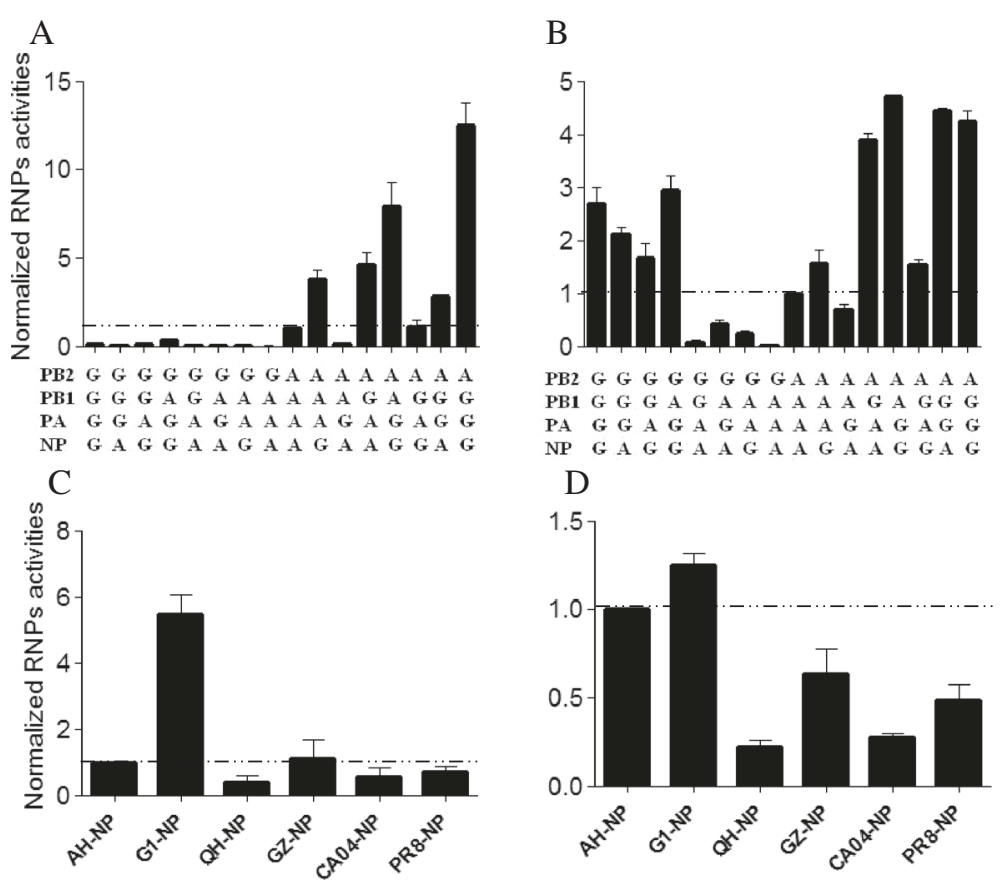

Figure 1 Normalized polymerase activities of recombinant polymerase complexes between A/Quail/Hongkong/G1/1997 (H9N2) and A/Anhui/1/2013 (H7N9) (A \& B), or different NPs in the backbone of A/Anhui/1/2013 (H7N9) PB2/PB1/PA plasmids (C \& D). RNP activities were measured in triplicate based on a Gluc reporter system and normalized to $\mathrm{AH} 1 \mathrm{RNP}$ activity at $33^{\circ} \mathrm{C}(\mathbf{A}, \mathbf{C})$ and $37^{\circ} \mathrm{C}(\mathbf{B}, \mathbf{D})$. Abbreviations in $\mathbf{A} \& \mathbf{B}$ : G, A/Quail/Hongkong/G1/1997; A, A/Anhui/1/2013; Abbreviations in C \& D: AH, A/Anhui/1/2013 (H7N9, AH1); G1, A/Quail/Hongkong/G1/ 1997 (H9N2, G1); QH, A/bar-headed goose/Qinghai/1/2005 (H5N1); GZ, A/Guangzhou/333/1999 (H9N2); CA04, A/California/04/2009 (2009pdmH1N1); and PR8, A/Puerto Rico/8/1934 (H1N1). Results are representative of three independent experiments. 

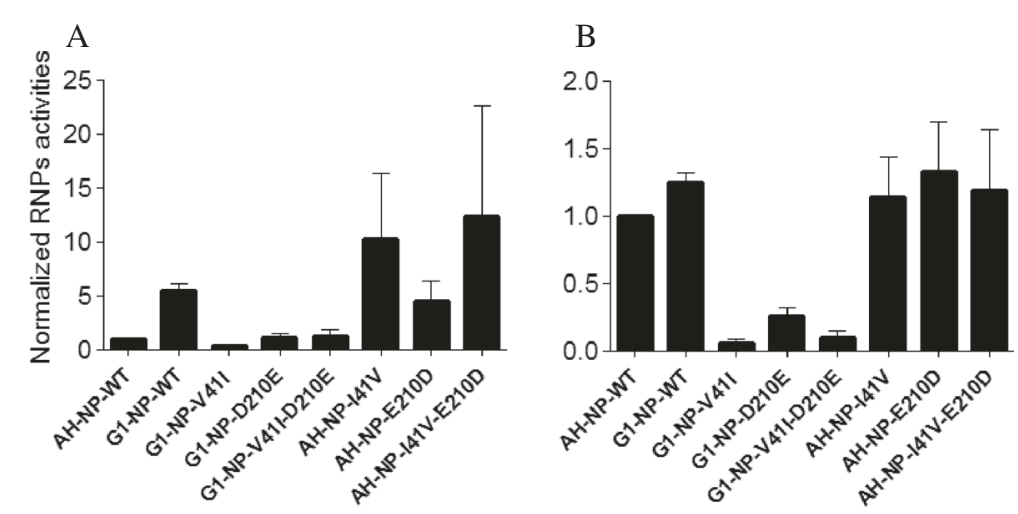

Figure 2 Viral RNA polymerase activities of NP-411/41V and/or NP-210E/210D in 293T cells in the backbone of A/Anhui/1/2013 (H7N9). Luciferase-based minigenome reporter assays were used to measure polymerase activity in $293 \mathrm{~T}$ cells at $33^{\circ} \mathrm{C}$ (A) or $37^{\circ} \mathrm{C}$ (B). Cells were co-transfected with Gluc reporter plasmid and expression plasmids PB2, PB1, and PA of A/Anhui/1/2013 (H7N9), plus different NPs to generate different viral RNPs. After culturing at $33^{\circ} \mathrm{C}$ or $37^{\circ} \mathrm{C}$ for $24 \mathrm{~h}$, Gaussia luciferase production was measured and normalized to AH1 activity. Results are presented as mean \pm SEM and are representative of three independent experiments.

other five NPs contained 41I and 210E (Additional file 1: Figure S1). To investigate whether the NP-41V and/or NP-210D mutations affect the enzymatic activity of RNPs, mutations NP-41V and/or NP-210D were introduced into the AH1-NP plasmid using a Site-Directed Mutagenesis Kit (Saibaisheng, Beijing, China). Conversely, mutations NP-41I and/or NP-210E were introduced into the G1-NP plasmid to generate mutant segments. The presence of the introduced mutation and the absence of additional unwanted mutations were verified by sequencing the entire plasmids. We then analyzed the activities of the recombinant RNP composed of AH1-PB2, AH1-PB1, AH1-PA, and various NPs (AH1NP-WT, AH1-NP-I41V, AH1-NP-E210D, AH1-NPI41V-E210D, G1-NP-WT, G1-NP-V41I, G1-NP-D210E, and G1-NP-V41I-D210E) in 293T cells at different temperatures using a mini-genome replication assay. Similar to the results exhibited in Figure 2, G1-NP-WT increased AH1-RNP activity at both $33^{\circ} \mathrm{C}$ and $37^{\circ} \mathrm{C}$. Little effect was observed with G1-NP-V41I and/or G1-NP-D210E at $33^{\circ} \mathrm{C}$, but reduced activity of $\mathrm{V} 41 \mathrm{I}$ and $\mathrm{D} 210 \mathrm{E}$ was shown at $37^{\circ} \mathrm{C}$. Likewise, G1-NP with V41I and D210E decreased the G1-RNP-WT activities (Additional file 2: Figure S2). Moreover, AH1-NP with mutations I41V and/or E210D exhibited 5-20 fold increased RNP activity of AH1-WT at $33^{\circ} \mathrm{C}$ (Figure 2). These results indicate that residues $41 \mathrm{~V}$ and $210 \mathrm{D}$ in NP proteins can enhance RNP activities of AH1 (H7N9), especially at $33^{\circ} \mathrm{C}$.

To investigate the effect of NP-41V and/or 210D on virus replication, recombinant viruses were generated with reverse-genetics as described previously [21]. For biosafety concerns, the four rescued viruses were performed using G1 (H9N2) backbones: rgG1-WT, rgG1NP-V41I, rgG1-D210E, and rgG1- NP-V41I-D210E.
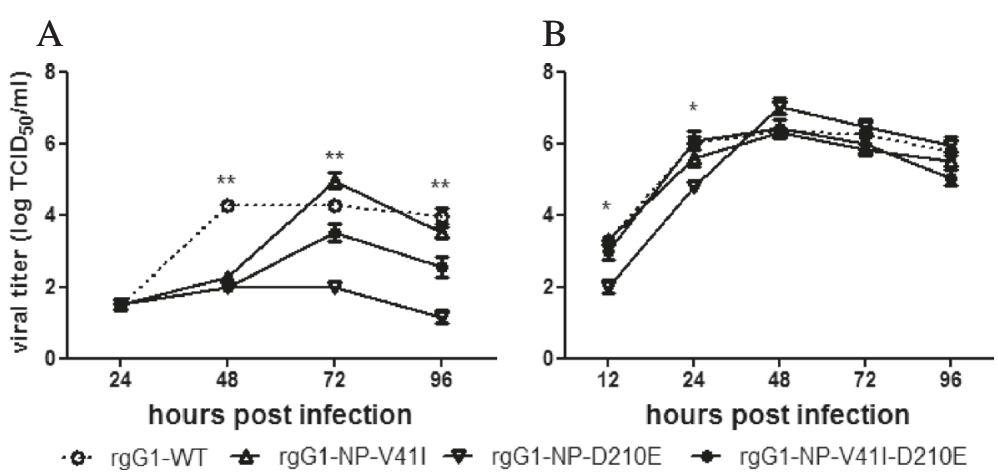

Figure 3 Replication kinetics of recombinant viruses rgG1-WT, rgG1-NP-V411, rgG1-NP-D210E, and rgG1-NP-V411-D210E in MDCK cells at 33ㄷ (A) or $37^{\circ} \mathrm{C}$ (B). Confluent monolayers of the various cell lines were inoculated with rgG1-WT, rgG1-NP-V411, rgG1-NP-D210E, or rgG1-NP-V411-D210E viruses. Cultured supernatants were harvested at 12, 24, 48, 72, and 96 hpi. Virus titers were determined by TCID 50 assay using MDCK cells. Results are presented as mean \pm SEM and are representative of three independent experiments. ${ }^{*}, p<0.05$ and ${ }^{*}, p<0.001$, compared the value of rgG1-NP-D210E with rgG1-WT. 
Table 1 Database search for NP-41I/V and/or NP-210D/E mutations in virus isolates from nature

\begin{tabular}{|c|c|c|c|c|c|c|}
\hline Mutations & Human & Swine & Avian & Canine & Equine & Other residues \\
\hline NP-41V & 6 & 14 & 197 & 42 & 98 & $I(13,763), A(2), G(3), K(1), M(1), Q(8), T(6), Y(1)$ \\
\hline \multicolumn{7}{|l|}{$(n=357)$} \\
\hline NP-210D & 9 & 4 & 143 & 0 & 0 & $E(13960), G(2), N(9), P(3), Q(2), R(3), X(7)$ \\
\hline \multicolumn{7}{|l|}{$(n=156)$} \\
\hline$N P-41 V+210 D$ & 6 & 0 & 19 & 0 & 0 & - \\
\hline$(n=25)$ & & & & & & \\
\hline
\end{tabular}

MDCK cells were infected with rescued viruses at a multiplicity of infection (MOI) of 0.001 , and incubated in the appropriate medium containing $2 \mathrm{mg} / \mathrm{L} \mathrm{N}$-p-tosylL-phenylalaninechloromethyl ketone-treated (TPCK) tryp$\sin$ (Sigma, Saint Louis, MO, USA) at 33 or $37^{\circ} \mathrm{C}$. At 12 , $24,48,72$, and 96 hours post inoculation (hpi), supernatants were harvested and virus titers were determined using MDCK cells, as described previously [22]. As shown in Figure $3 \mathrm{~B}$, at $37^{\circ} \mathrm{C}$, the D210E substitution in the NP protein significantly decreased the replication ability of rgG1-WT at early stages post infection (12 and 24 hpi $(p<0.05 ; n=3)$, although all four viruses demonstrated comparable growth capability at later stages. Mutation NP-V41I alone or in combination with D210E, which showed decreased polymerase activity, exhibited little impact on the growth of rescued virus at $37^{\circ} \mathrm{C}$. The apparent discrepancy between the minigenome reporter assay and the in vitro virus replication assay in our study may be related to the different parameters; whereas mRNA synthesis and reporter protein expression is the primary readout in minigenome assays, for efficient virus replication, a proper balance between the syntheses of cRNA, vRNA, and mRNA is required. However, at $33^{\circ} \mathrm{C}, \mathrm{G} 1$ viruses with the D210E mutation displayed a replication defect (Figure 3A). The rgG1-WT virus demonstrated better replication ability to the other three viruses, except G1-NP-V41I of $72 \mathrm{hpi}$. These data indicate a growth advantage of recombinant viruses of rgG1-WT containing NP-41V and NP-210D in MDCK cells at $33^{\circ} \mathrm{C}$, which corresponds to their high polymerase activity in 293T cells.

Sequence alignment of available NP sequences of avian and mammalian influenza $A$ viruses in NCBI showed that in 14,142 NP sequences, 357 (2.5\%) possess NP-41V and $156(1.1 \%)$ possess NP-210D (Table 1). Most of the viruses with NP-41V or NP-210D residues were avian influenza viruses (197/357 and 143/156, respectively). However, few NP-41V or NP-210D residues were found in mammalian influenza viruses, including those of human and swine-origin viruses. In addition, no such substitutions have yet been found in the novel H7N9 viruses (data not shown). Despite this, our study revealed that compared with NP-210D, NP-210E could reduce the RNP activity of AH1 (H7N9) and G1 (H9N2) viruses, and could also inhibit the replication of G1 viruses, especially at $33^{\circ} \mathrm{C}$. However, compared with NP-41V, although viruses with NP-41I were associated with decreased RNP activity, no significant variation in virus growth ability was observed. Therefore, mutations NP$41 \mathrm{~V}$ and/or NP-210D may increase the growth capability of the AH1 (H7N9) virus, particularly in low temperature. Reassortants between G1-like and Y280-like viruses are not rare [17-19]. Given the continuous mutation and dynamic reassortment $[16,23]$ of H7N9 viruses in both human and avian hosts, the possibility for these viruses to obtain these two residues or the entire NP gene of G1-like viruses cannot be excluded. Therefore, despite the absence of amino acids $41 \mathrm{~V}$ and 201D in the $\mathrm{NP}$ of current H7N9 viruses, reassortants with the entire G1-like NP gene and substitutions of these two residues in the NP protein are worthy of attention.

\section{Additional files}

Additional file 1: Figure S1. Sequence alignment of the NP genes of six viruses: AVAnhui/1/2013 (H7N9, AH1), A/California/04/2009 (2009pdmH1N1, CA04), A/Puerto Rico/8/1934 (H1N1, PR8), A/Guangzhou/333/1999 (H9N2, GZ), A/bar-headed goose/Qinghai/1/2005 (H5N1, QH), and A/Quail/ Hong Kong/G1/1997 (H9N2, G1).

Additional file 2: Figure S2. Viral RNA polymerase activities of NP-41// NP-41V and/or NP-210E/210D in the background of A/Quail/Hongkong/ G1/1997 (H9N2). 293 T cells were co-transfected with Gluc reporter plasmid and expression plasmids PB2, PB1, and PA of A/Quail/Hongkong/G1/1997 (H9N2), plus G1 NP with different mutations. After culturing at $37^{\circ} \mathrm{C}$ for $24 \mathrm{~h}$, Gaussia luciferase production was measured and normalized to G1 activity. Results are presented as mean \pm SEM and are representative of three independent experiments.

\section{Abbreviations}

Gluc: Gaussia luciferase; RNP: Ribonucleoprotein; RdRp: Influenza RNAdependent RNA polymerase; PB2: Polymerase basic 2 protein; PB1: Polymerase basic 1 protein; PA: Polymerase acidic protein; NP: Nucleoprotein; p.i.: postinfection; MDCK: Madin-Darby canine kidney.

\section{Competing interests}

The authors declare that they have no competing interest. 


\section{Authors' contributions}

SYL designed the research; ZWF, ZXH, ZJF, and TJ performed research and analyzed data; ZWF wrote the paper; SYL revised the manuscript. All authors read and approved the final manuscript.

\section{Acknowledgements}

This study was supported by the National Nature Science Foundation of China (81341003) and the National Mega-projects for Infectious Diseases (2014ZX10004002)

Received: 2 February 2015 Accepted: 29 April 2015

Published online: 05 May 2015

\section{References}

1. Gao R, Cao B, Hu Y, Feng Z, Wang D, Hu W, et al. Human infection with a novel avian-origin influenza A (H7N9) virus. N Engl J Med. 2013;368:1888-97.

2. Zhu H, Wang D, Kelvin DJ, Li L, Zheng Z, Yoon SW, et al. Infectivity, transmission, and pathology of human-isolated H7N9 influenza virus in ferrets and pigs. Science. 2013;341:183-6.

3. Zhang Q, Shi J, Deng G, Guo J, Zeng X, He X, et al. H7N9 influenza viruses are transmissible in ferrets by respiratory droplet. Science. 2013;341:410-4.

4. Watanabe T, Kiso M, Fukuyama S, Nakajima N, Imai M, Yamada S, et al. Characterization of H7N9 influenza A viruses isolated from humans. Nature. 2013;501:551-5.

5. Belser JA, Gustin KM, Pearce MB, Maines TR, Zeng H, Pappas C, et al. Pathogenesis and transmission of avian influenza A (H7N9) virus in ferrets and mice. Nature. 2013;501:556-9.

6. Li Q, Zhou L, Zhou M, Chen Z, Li F, Wu H, et al. Preliminary Report: Epidemiology of the Avian Influenza A (H7N9) Outbreak in China. N Engl J Med. 2013;370:520-32

7. Gao HN, Lu HZ, Cao B, Du B, Shang H, Gan JH, et al. Clinical findings in 111 cases of influenza A (H7N9) virus infection. N Engl J Med. 2013:368:2277-85.

8. Hatta M, Gao P, Halfmann P, Kawaoka Y. Molecular basis for high virulence of Hong Kong H5N1 influenza A viruses. Science. 2001;293:1840-2.

9. Labadie K, Dos Santos AE, Rameix-Welti MA, van der Werf S, Naffakh N. Host-range determinants on the PB2 protein of influenza A viruses control the interaction between the viral polymerase and nucleoprotein in human cells. Virology. 2007;362:271-82

10. Hatta M, Hatta Y, Kim JH, Watanabe S, Shinya K, Nguyen T, et al. Growth of H5N1 influenza A viruses in the upper respiratory tracts of mice. PLoS Pathog. 2007:3:1374-9.

11. Massin P, van der Werf S, Naffakh N. Residue 627 of PB2 is a determinant of cold sensitivity in RNA replication of avian influenza viruses. J Virol. 2001;75:5398-404

12. Steel J, Lowen AC, Mubareka S, Palese P. Transmission of influenza virus in a mammalian host is increased by PB2 amino acids $627 \mathrm{~K}$ or $627 \mathrm{E} / 701 \mathrm{~N}$. PLoS Pathog. 2009:5:e1000252.

13. Van Hoeven N, Pappas C, Belser JA, Maines TR, Zeng H, Garcia-Sastre A, et al. Human HA and polymerase subunit PB2 proteins confer transmission of an avian influenza virus through the air. Proc Natl Acad Sci U S A. 2009;106:3366-71.

14. Qi X, Qian YH, Bao CJ, Guo XL, Cui LB, Tang FY, et al. Probable person to person transmission of novel avian influenza A (H7N9) virus in Eastern China, 2013: epidemiological investigation. BMJ. 2013;347:f4752.

15. Zhou J, Wang D, Gao R, Zhao B, Song J, Qi X, et al. Biological features of novel avian influenza A (H7N9) virus. Nature. 2013:499:500-3.

16. Wang D, Yang L, Gao R, Zhang X, Tan Y, Wu A, et al. Genetic tuning of the novel avian influenza $A(H 7 N 9)$ virus during interspecies transmission, China, 2013. Euro Surveill. 2014; 19(25)

17. Zhang P, Tang Y, Liu X, Liu W, Zhang X, Liu H, et al. A novel genotype H9N2 influenza virus possessing human H5N1 internal genomes has been circulating in poultry in eastern China since 1998. J Virol. 2009;83:8428-38.

18. Li C, Yu K, Tian G, Yu D, Liu L, Jing B, et al. Evolution of H9N2 influenza viruses from domestic poultry in Mainland China. Virology. 2005;340:70-83.

19. Li KS, Xu KM, Peiris JS, Poon LL, Yu KZ, Yuen KY, et al. Characterization of H9 subtype influenza viruses from the ducks of southern China: a candidate for the next influenza pandemic in humans? J Virol. 2003;77:6988-94.

20. Zhu W, Zhou J, Qin K, Du N, Liu L, Yu Z, et al. A reporter system for assaying influenza virus RNP functionality based on secreted Gaussia luciferase activity. Virol J. 2011:8:29
21. Fodor EDL, Engelhardt OG, Palese P, Brownlee GG, García-Sastre A. Rescue of influenza A virus from recombinant DNA. J Virol. 1999;73:9679-82.

22. Reed $L M$. H. A simple method of estimating fifty percent endpoints. Am J Hyg. 1938;27:493-7.

23. Zhu W, Shu Y. Genetic tuning of avian influenza A (H7N9) virus promotes viral fitness within different species. Microbes Infect. 2014;17(2):118-22.

\section{Submit your next manuscript to BioMed Central and take full advantage of:}

- Convenient online submission

- Thorough peer review

- No space constraints or color figure charges

- Immediate publication on acceptance

- Inclusion in PubMed, CAS, Scopus and Google Scholar

- Research which is freely available for redistribution

Submit your manuscript at www.biomedcentral.com/submit 